\title{
A REVIEW OF THE EFFECTS OF CHANGES IN THE VOID FRACTION OF THE SUPERHEATED REGION ON THE TEV OPERATION AND EVAPORATOR STABILITY
}

\begin{abstract}
R. A. Ramos ${ }^{a}$,
and J. Castrob

${ }^{\mathrm{a}}$ Universidade Federal do Vale do São

Francisco

Mechanical Engineering Department José de Sá Maniçoba Ave, Petrolina - PE, 56304-917, Brasil ramosavelar@gmail.com

${ }^{\mathrm{b}}$ Universidade Federal do Vale do São

Francisco

Mechanical Engineering Department

ABSTRACT

A level of superheat is necessary to ensure proper operation of vaporcompression refrigeration systems. An overly superheated vapor prior to entering the compressor can render the system inefficient, while inadequate superheat can result in evaporator instability and compressor damage. The void fraction present in the suction line is directly related to evaporator stability and the hunting phenomenon in the thermostatic expansion valve (TEV). This article aims at reviewing superheated region-related researches in the field of refrigeration as they relate to the operation of the TEV and the stability of the evaporator. In a first part, literature review will explain the causes of the void fraction in the superheated region and the second part describes the effects of the lubricant oil on the void fraction. The third part of this article is a review of the effects of the superheated region on the TEV and on evaporator stability, explaining the causes of the hunting phenomena and evaporator instability.
\end{abstract}

José de Sá Maniçoba Ave,

Petrolina - PE, 56304-917, Brasil

Received: August 16, 2016

Revised: September 19, 2016

Accepted: October 21, 2016

Keywords: superheat, void fraction, maldistribution, oil, hunting, instability

\section{NOMENCLATURE \\ $\mathrm{m}_{\mathrm{t}} \quad$ mass flow rate \\ $\mathrm{f}_{\mathrm{q}} \quad$ evaporator heat flux}

\section{Greek symbols}

$\eta \quad$ effective liquid dry-out point

$\theta_{\max }$ maximum MSS amount

$\theta_{\min }$ minimum MSS amount

\section{Subscripts \\ $\max$ maximum \\ min minimum \\ q related to heat transfer \\ $\mathrm{t}$ time dependent}

\section{INTRODUCTION}

In the refrigeration and air-conditioning vapor compression systems superheating is the result of additional heat transfer from the environment to the system after the evaporation of the fluid inside the evaporator and through the suction pipes prior to entering the compressor. Depending on how the theoretical vapor-compression refrigeration system is defined, the analysis of the cycle does not account for such heat transfer, as it is assumed to exist no heat transfer in the pipes, and no additional heat is transferred after the fluid has been completely evaporated inside the evaporator.

Superheating plays an important role in the vapor-compression refrigeration cycle. It ensures that no liquid goes into the compressor, thus, protecting the compressor from damage. All refrigeration systems today are designed to account for some degree of superheat. However, high degrees of superheating can render the system inefficient in its operation. Therefore, maintaining the superheating of a system to a minimum can potentially decrease the size of the evaporator (Solberg et al. 2000).

Maintaining the superheat levels at a minimum is a challenge directly related to the means by which it is measured in a system. Most air-conditioning systems with a control signal today uses superheat as the variable to which the system will make changes in order to operate within its threshold of normal operation. This makes the measurement of superheat an important aspect of the operation and efficiency of the vapor-compression refrigeration cycle.

The objective of this paper is to review the effects of the superheated region in the TEV and the stability of the evaporator. The first section will consider the void fraction in the suction pipe and its causes and the second section considers the effects of the oil-refrigerant mixture in the superheated region. The third and final section will review the impact of the superheated region on the expansion device and on evaporator instability. 


\section{VOID FRACTION IN THE SUPERHEATED REGION}

Books of thermodynamics fundamentals consider the superheated vapor in the superheated region to be $100 \%$ vapor with some fraction of lubricant oil, both in equilibrium. However, studies have shown that only partial evaporation happens in the evaporator. (Wedekind et al. 1978; Solberg et al. 2000) The region is considered to be in nonequilibrium with saturated droplets entrained in the superheated vapor, thus, making the refrigerant quality less than 1. (Wedekind et al. 1978) By the time the fluid reaches the sensor of the expansion valve, when such sensors are used in vaporcompression refrigeration systems, there is not enough time for thorough evaporation of these droplets. (Solberg et al. 2000) There is some measure of void fraction within this region.

Previous studies of the vapor volumetric concentration, or void fraction, include Zuber and Staub (1966) and Hancox and Nicoll (1971). Zuber and Staub (1966) presented the solutions to void fraction propagation equations to variations in power, fluid flux, pressure, thermodynamic nonequilibrium, vapor and liquid compressibility, and body forces. Hancox and Nicoll (1971) also presented void distribution methods, extending the analysis to include non-valid fully developed void, velocity, and enthalpy flow profiles assumption.

Wedekind and Stoeker (1968) were one of the pioneers to study superheat stability. (Wedekind and Stoecker 1968) His experiment evaluated the location of the last droplet seen in a straight glass tube heat exchanger. The result was that the region's distribution was determined with a stochastic function describing the unpredictable behavior of the region's length. Even after the effective liquid dryout point, the point where we would consider a quality 1 state, there still exists some fraction of liquid. Later studies observed the same phenomenon, proving Wedekind to be correct with his findings (Barnhart and Peters 1992).
The stochastic nature of the evaporating flow process causes unpredictability in the length of the two-phase region. Even for what is generally considered steady state flow, the length of this region will still fluctuate. Part of this condition happens because of the complicated nature of two-phase flow and the imperfect flow distribution within the evaporator. Figure 1 shows the measured oscillation of the end position of the evaporator region, as measured by Wedekind and Stoecker (1968).

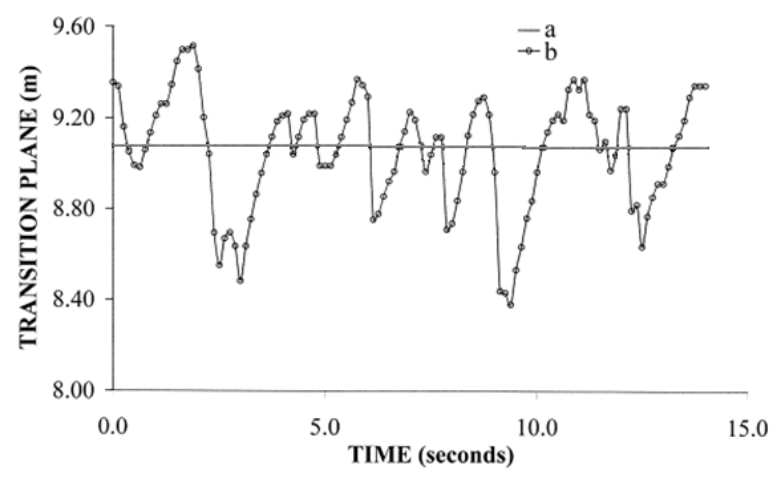

Figure 1. Measured oscillations at the end position of the evaporator region with (a) being the mean position of transition point and (b) the actual motion as measured experimentally. (Wedekind and Stoecker 1968).

\section{Two-Phase Flow Nature}

The two-phase evaporating flow is composed of a variety of complicated flow patterns, especially if complete evaporation occurs. These flow patterns have a great impact on the evaporating process. The heat transfer and the pressure drop depends of the nature of the flow, resulting in the instability of the superheat degree leaving the evaporator. Figure 2 shows a schematic of a two-phase evaporating flow.

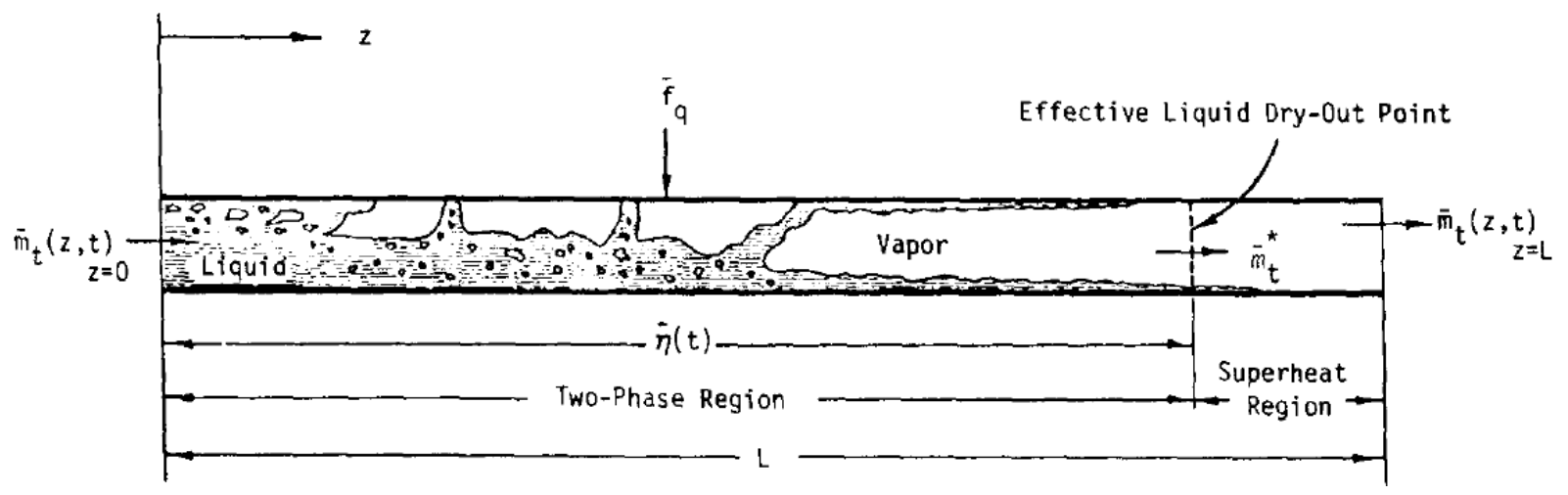

Figure 1. Schematic of a two-phase evaporating flow (Wedekind et al. 1978). 
The liquid droplet content of the fluid leaving the evaporator influences the level of superheat being measured. However, greater influence occurs when the liquid is present as waves, instead of droplets. (Van der Meer 1987) These waves will have a better contact with the wall of the suction pipe, changing the temperature of the bulb, causing the thermostatic expansion valve (TEV) to oscillate at a much greater rate.

This wave flow pattern according to Wallis and Dobson (1973) happens as follows: The liquid and vapor velocities differs from each other in two-phase flow regimes. Vapor travels at a greater velocity than the liquid. At a certain velocity difference, the lower pressure in the center of the tubes due to the higher velocity of the vapor, causes ripples to be formed. The Bernoulli forces from the vapor flow at bigger velocity differences results in the growth of these ripples to waves. In the transversal area where these waves are located, the vapor area section is diminished, which causes the vapor velocity to grow, lowering the pressure and keeping the waves up. A large wave can fill the transversal area section of the tube. This is also called slug flow. These waves are blown forward by the vapor and propelled downwards. Figure 3 illustrates the process of the wave formation. When the waves come in contact with the liquid transition point, it will still have its lower temperature. (Van der Meer 1987) Barnhart and Peters (1995), who conducted a study on entrained liquid carry-over from a serpentine evaporator, also saw a liquid surplus towards the exit of the evaporator resulting in clusters of droplets at irregular intervals. This surplus was transported by slugs, or waves, originating near the inlet of the evaporator in the liquid-rich region. With the liquid's lower temperature, sharp decreases in superheat level was accounted for at these irregular intervals, having a direct effect on the superheated region.

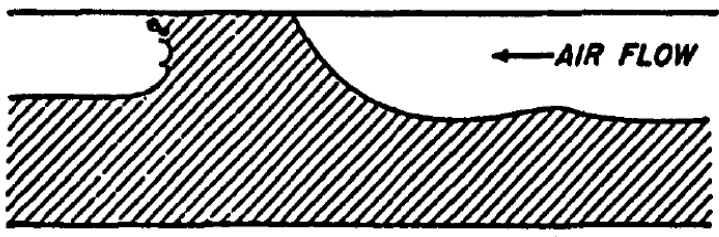

(o)

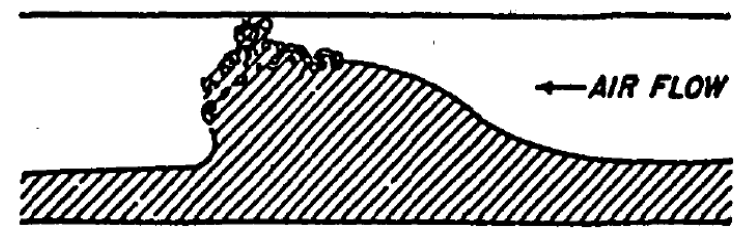

(b)

Figure 2. Wave flow formation (Wallis and Dobson 1973).

\section{Refrigerant Maldistribution}

The majority of commercially available evaporators today use a parallel channel configuration in order to increase its capacity in a limited amount of space. Inlet headers are used to assure flow distribution. The efficiency of these evaporators rely on the even distribution of fluid in the parallel channels. However, non-uniform distribution generally occurs, decreasing the effectiveness of the heat exchanger. This is especially true for evaporators since the supplied refrigerant is usually in a two-phase state. Mueller (1987) evaluated the thermal performance loss of the evaporator of most usual applications in 5-10\%. Fluid maldistribution also results in a lowered coefficient of performance (COP) of the system.

Groll et al. (2011) measured on a combination of experiments and simulations the maldistribution in test circuits. It was found that specific circuits had $61 \%$ less flow than the average while others had $45 \%$ more than the average. The maldistribution of refrigerant can happen in both single and two phase flow. However, due to the different properties of vapor and liquid, two phase flows are notably unfavorable since there is phase separation in the header. (Zou and Hrnjak 2014a) This uneven distribution creates unwanted superheated regions with lower heat transfer coefficients and high temperatures in the evaporator. Considering that some tubes reach a superheated state, other parallel tubes deliver refrigerant in a two-phase state to the outlet header of the evaporator, which can cause excess liquid to spill from the evaporator. (Shannon et al. 2001) This superheated vapor has to compensate for the two-phase refrigerant. However, overly superheated tubes can be very detrimental to evaporator performance. (Tuo and Hrnjak 2013)

Overall, the causes of evaporator maldistribution can be classified into two types: geometric factors and operational factors. Geometrical factors can encompass differences in diameter and length of parallel paths, pressure drop in headers due to its geometry, the coupling arrangement between the channels and the header, and the orientation and position with respect to gravity. Operational factors include quality induced maldistribution, flow patterns, mass flow rates, and changes in lubricating oil distribution. (Mader et al. 2015; Mueller 1987; Mueller and Chiou 1988; Shannon et al. 2001; Tuo and Hrnjak 2013).

\section{EFFECT OF THE LUBRICANT OIL MIXTURE IN THE SUPERHEATED REGION}

The primary role of the lubricant oil in the vapor compression refrigeration system is to ensure the efficacy and normal operation of the compressor by lubricating its moving parts. The lubricant oil also serves as a noise limiter, a tightness element, and in 
some situations, it is used for compressor cooling, working as a heat transfer medium. (Youbi-Idrissiand and Bonjour 2008) Even though its role is only related to the compressor, inevitably, some amount of oil will flow with the refrigerant throughout the system. It flows through the entire refrigeration system along with the refrigerant as droplets. (Wujek 2011)

The presence of oil in the system causes changes in the pressure drop and heat transfer along system components, and alters the thermodynamic equilibrium and transport properties of the refrigerant (such as density, saturated temperature, thermal conductivity, viscosity, etc.). (Li and Hrnjak 2015) These changes will have an impact on the superheat of the system.

The three important effects on the superheated region caused by the lubricant oil are the changes in heat transfer properties, changes in the flow patterns, and increases in the refrigerant-side pressure drop. No consensus has been reached by the scientific community on the effect of oil addition on the heat transfer properties. However, experimental evidence can be found of its effect on flow patterns and pressure drop.

Various studies have been conducted on twophased flow patterns of refrigerants. (Haverkamp et al. 2006; Chinnov and Kabov 2006; Saisorn and Wongwises 2008; Shao et al. 2009; Rebrov 2010; Awad and Muzychka 2014) However, this is not true regarding refrigerant-oil mixtures due to the difficulties found in its evaluation and experimentation. Nonetheless, the changes in flow pattern by the addition of oil can be explained through foaming. (Li and Hrnjak 2015) Lubricant oil foaming can also affect the heat transfer in the evaporator. (Youbi-Idrissiand and Bonjour 2008)

Worsøe-Schmidt (1960) observed that when oil was added to the refrigerant, increased stratifiedwavy flow was detected in the wetted perimeter of the wall, which can be explained by the increased surface tension of the refrigerant-oil mixture. Figure 4 shows the evolution of the flow pattern of an R12/oil mixture at the inlet (a), middle (b) and outlet (c) of his evaporator. Studies have shown that the surface tension can be increased by as much as $18 \%$ (Bandarra Filho et al. 2008). This effect on surface tension can also explain the pressure drop increase in system components and lines.

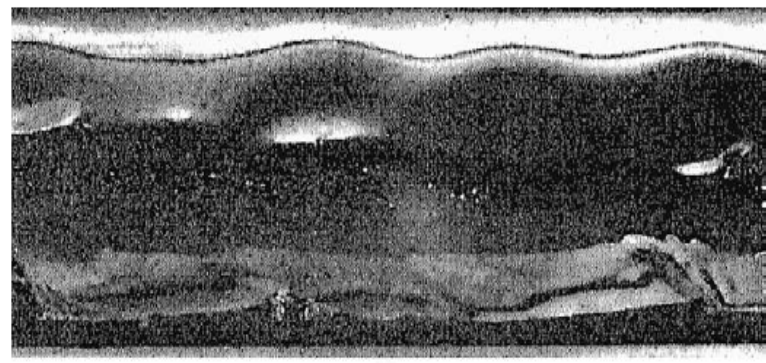

a

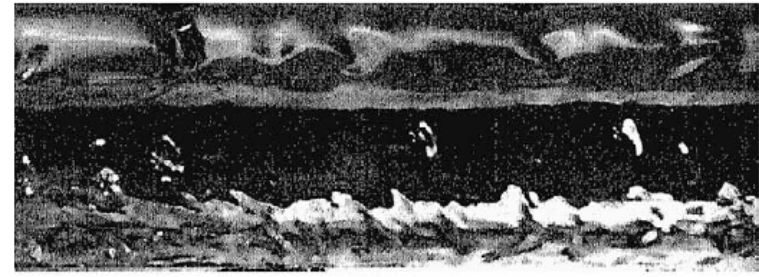

b

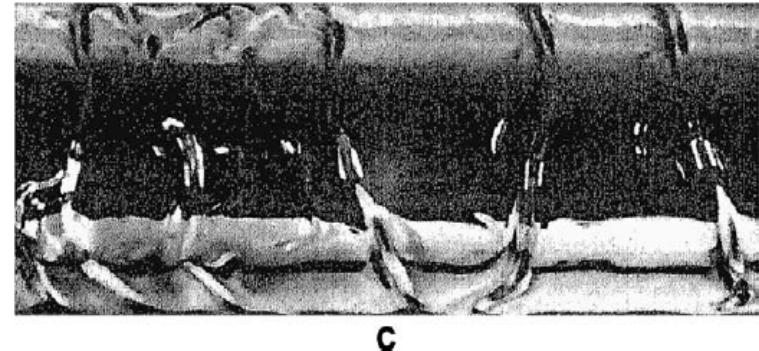

Figure 3. Visualization of the evolution of the flow pattern of R-12/oil mixture at the inlet (a), middle

(b), and outlet (c). (Worsoe-Schmidt 1960).

Wei et al. (2007) studied the influences of oil on refrigerant flow boiling inside horizontal smooth tubes with inside diameters of $6.34 \mathrm{~mm}$ and $2.50 \mathrm{~mm}$ and found alterations in the flow regime of the refrigerant-oil mixture in the different diameter tubes. They found wavy, wavy-annular, annular and mistannular flow pattern in the $6.34 \mathrm{~mm}$ inside diameter tube and slug-annular and annular flow pattern in the $2.50 \mathrm{~mm}$ inside diameter tube.

These two-phase flow pattern alterations are very important in the evaporator. The altered flow regime can cause maldistribution in the parallel tubes, which in turn, causes unwanted superheated regions with lower heat transfer coefficients (Zou and Hrnjak 2014b). Burr et al. (2005) visualized flow regime of R134a and polyolester oil mixture. It was observed that maldistribution was exacerbated by the oil addition and the void fraction was depressed by the presence of lubricant.

The other impact of the lubricant oil addition is on the pressure drop in the liquid phase of high quality regions in the evaporator. Since the oil is nearly non-volatile, it remains in the liquid phase. As the liquid refrigerant vaporizes, the oil remains in the liquid form, causing a high concentration of oil in the liquid phase near the end of the evaporation process (Bandarra Filho et al. 2008). Thome (1995) observed in many experiments that the effect of oil concentrations only became important in vapor qualities above $85 \%$. Since oil has a higher viscosity than refrigerants, accumulation of oil tends to occur at the end of evaporators, causing increased pressure drops and decreased heat transfer. (Bandarra Filho et al. 2008) This in turn can cause an increase in the liquid carry-over length in the suction pipe.

\section{IMPACT ON COMPONENTS}

\section{Expansion Device}


Expansion devices are important components of the vapor compression refrigeration systems. The most commonly used devices are the capillary tube and the TEV, or the electronic expansion valve (EEV), which functions with the same principal as the TEV. Their primary functions are to decrease the pressure at the entrance of the evaporator and to regulate the mass flow of refrigerant.

The TEV uses superheat as its control signal in order to adjust the valve opening and closing. The remote thermal bulb attached to the suction line wall near the evaporator exit is used to receive this signal. Since liquid carry-over has to be avoided in order to maintain safe operation of the compressor, a finite level of superheat is desired. This finite desirable superheat is called the static superheat setting (SSS) (Mithraratne and Wijeysundera 2003) and can be adjusted by changing the tension of the spring in the TEV. When the superheat level is above or below the set point, the intervention of the TEV has to bring the superheat to the desirable level.

The minimum amount of superheat level acceptable by the system is directly related to the means by which the superheat is measured. (Solberg et al. 2000) If the SSS is too high, loss of efficiency can occur, and if too low, the safe operation of the compressor can be compromised along with the stability of the system. Thus, it is of the uttermost importance that the TEV remote thermal bulb measure a reliable representation of the level of superheat in the system. This will ensure the effective and efficient use of the TEV.

As explained in the previous section, the fluid leaving the evaporator is in a non-equilibrium state. The liquid entrained in the superheat region by means of liquid droplets or waves has both lower temperatures and higher heat transfer coefficients. When in contact with the wall section where the thermal bulb is located, it will render a false representation of the superheat level. In the case of liquid droplets, there needs to be a relatively even distribution throughout the cross sectional area where the bulb is located in order to minimize its effect of the measurement. The slugs that originate in the liquid-rich region of the evaporator, on the other hand, have a greater impact on the measurement of superheat, therefore, complicating the use of exit superheat reading in control strategies (Barnhart and Peters 1995).

The result of this phenomena is that the signal from the thermal bulb will exhibit large variances. The bulb can be measuring temperatures anywhere from the saturation temperature of the liquid droplets or slugs to the temperature of the superheated vapor. When a large variance in the signal occurs, it may cause the controller to hunt. When hunting takes place, the valve will fluctuate from open to close in a sustained manner, changing the refrigerant flow rate continuously, resulting in the change of evaporator pressure and superheat level. (Mithraratne and
Wijeysundera 2003) Figure 5 shows the variation of superheat temperature under hunting conditions for different static superheat settings (SSS).

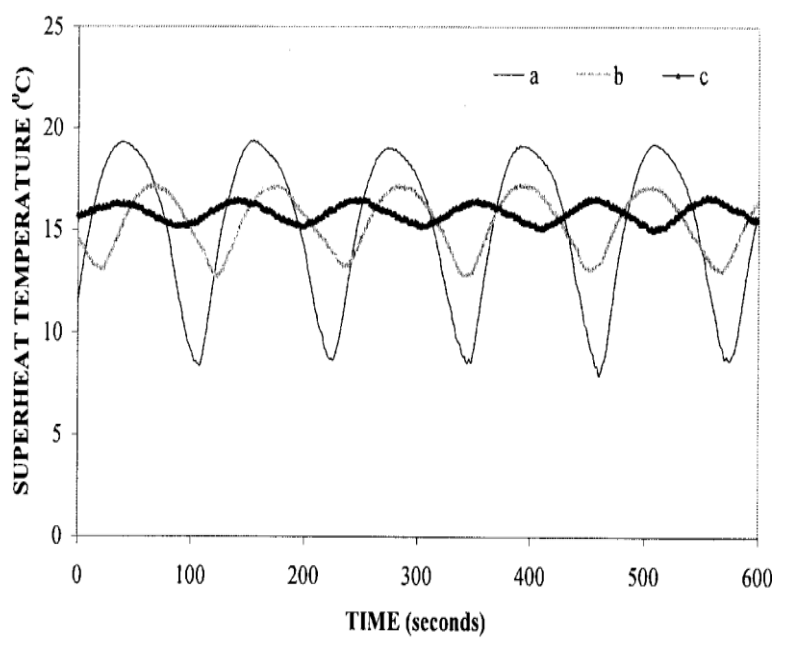

Figure 4. Variation of superheat temperature under hunting conditions. (a) SSS1, (b) SSS2, (c) SSS3 under condition: SSS $1<\mathrm{SSS} 2<\mathrm{SSS} 3$. (Mithraratne and Wijeysundera 2003).

The two main factors that contribute to the hunting behavior of the TEV are (i) the unpredictable oscillation of the transition point between the twophase region and the superheated vapor region inside the evaporator along its internal channels (Wedekind 1971), and (ii) the system's response to fluctuations in the cooling load (Mithraratne and Wijeysundera 2003).

\section{Evaporator Instability}

The operating stability in a vapor compression refrigeration system strongly depend on the degree of superheat. It is understood that having low superheat levels results in the efficient use of energy of the system. However, when running at low superheats, unstable behavior of the system may occur (Shang et al. 2015).

The concept of the minimum stable superheat (MSS) line was created by Huelle $(1967 ; 1972)$ in light of the unstable behavior observed at low superheat levels. Huelle found that there has to be a minimum degree of superheat in the system for a constant cooling capacity in order to achieve stable running conditions of the evaporator in systems with TEV. He observed that the hunting behavior occurred often when running at low superheat levels. Figure 6 below shows the MSS line and its relationship to stable and unstable conditions developed later by Huelle (1972). The MSS line was confirmed experimentally by Chen et al. (2002), proposing that the variation of flow type and heat transfer coefficient are also reasons for the existence of the MSS line. 


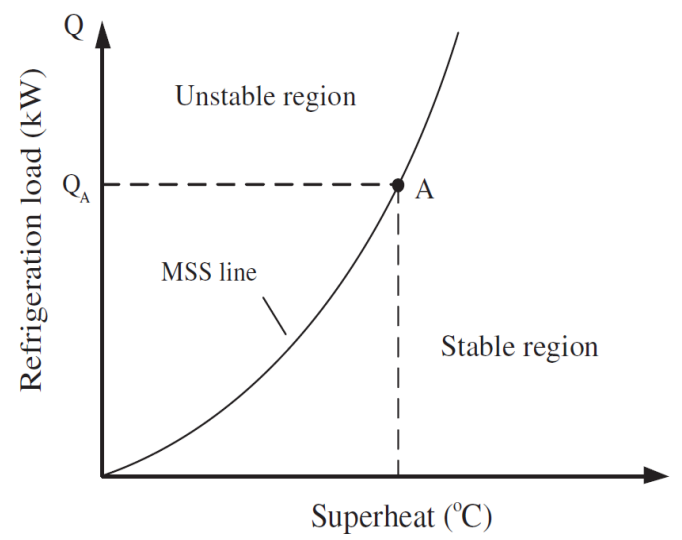

Figure 5. MSS line proposed by Huelle (1972).

When operating conditions are at the right of the MSS line, as seen in Fig. 6, the evaporator will work at stable conditions; when the system is running to the left of the MSS line, the evaporator will work at unstable conditions; and when running on the MSS line, the evaporation is at the critical point between unstable and stable conditions. Huelle believed that the line is influenced by the characteristics of the system. Thus, extrapolating a MSS line from one system to another can result in lack of precision. (Chen et al. 2008)

At the time, the MSS theory was developed for single speed compressors. Varying compressor speed is known to reduce energy consumption in refrigeration systems and it is becoming widely used today. The problem with the MSS line for variable speed compressor is that while the speed of the compressor varies, and the cooling capacity changes in result, the SSS will normally remain the same.

Chen (2008) proposed a modified MSS line having a maximum and minimal MSS value for systems with variable speed compressors (VSC) and EEV. The modified MSS line is shown in Fig. 7. The suggested modified line is a piecewise curve with a minimum MSS amount, $\theta_{\min }$, and a maximum MSS amount, $\theta_{\max }$.

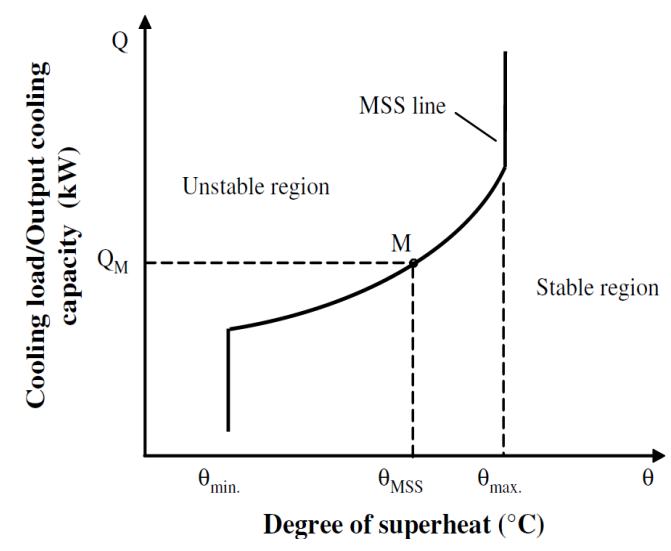

Figure 6. The modified MSS line proposed by Chen et al. (2008).
For stable operations, the superheat level should always be set in between the maximum and minimum values regardless of cooling loads, as running above the maximum value result in low efficiency and when running below the minimum value result in unstable operating conditions. It was also observed that decreasing compressor speeds may cause the hunting phenomenon during the change in the system. Thus, Chen stated to be beneficial to have smaller magnitude speed reductions (Chen et al. 2008).

\section{CONCLUSION}

In this brief review study, the impact of chances in the void fraction of the superheated region on the TEV operation and evaporator stability is analyzed. Explanation is given to the concept of void fraction and the length of the liquid dry-out point and its unpredictability. The complicated nature of twophase flow and the imperfect flow distribution are discussed in relation to the void fraction. A review of the effects of the oil-refrigerant mixture in the superheated region is presented. Even though there is no agreement in regards to the heat transfer effect of the addition of lubricant oil, the effect on flow patterns and pressure drop was considered. The final and main section presents the impacts of liquid carryover and degree of superheat, with their causes explained in the previous section, on the TEV and evaporator stability.

\section{REFERENCES}

Awad, M. M., and Muzychka, Y. S., 2014, Review and Modeling of Two-Phase Frictional Pressure Gradient at Microgravity Conditions, Interfacial Phenomena Heat Transfer, Vol. 2, No. 1, pp. 15-40.

Bandarra Filho, E. P., Cheng, L., and Thome, J. R., 2008, Flow Boiling Characteristics and Flow Pattern Visualization of Refrigerant/Lubricant Oil Mixtures, International Journal of Refrigeration, Vol. 32, pp. 185-202.

Barnhart, J. S., and Peters, J. E., 1992, An Experimental Investigation of Flow Patterns and Liquid Entrainment in a Horizontal-Tube Evaporator, ACRC, TR 28, University of Illinois at UrbanaChampaign.

Barnhart, J. S., and Peters, J. E., 1995, An Experimental Investigation of Entrained Liquid Carry-Over from a Serpentine Evaporator, International Journal of Refrigeration, Vol. 18, pp. 343-354.

Burr, J. D., Newell, T. A., and Hrnjak, P. S., 2005, Experimental Investigation of Viscous TwoPhase Flow in Microchannels, ACRC, TR-252, University of Illinois at Urbana-Champaign.

Cengel, Y. A., and Boles, M. A., 2006, Thermodynamics: an Engineering Approach, 5th Edition, McGraw-Hill Inc. 
Chen, W., Chen, Z., Zhu, R. Q., and Wu, Y. Z., 2002, Experimental Investigation of a Minimum Stable Superheat Control System of an Evaporator, International Journal of Refrigeration, Vol. 25, No. 8, pp. 1137-1142.

Chen, Y., Deng, S., Xu, X., and Chan, M., 2008, A Study on the Operational Stability of a Refrigeration System Having a Variable Speed Compressor, International Journal of Refrigeration, Vol. 31, No. 8, pp. 1368-1374.

Chinnov, E. A., and Kabov, O. A., 2006, Two Phase Flow in Pipes and Capillary Channels, High Temperatures, Vol. 44, No. 5, pp. 773-791.

Groll, E. A., Braun, J. E., and Bach, C. K., 2011, Optimizing Refrigerant Distribution in Evaporators - Final Report, California Energy Commission, Publication number: CEC-500-2013089.

Hancox, W. T., and Nicoll, W. B., 1971, A General Technique for the Prediction of Void Distributions in Non-Steady Two Phase Forced Convection, International Journal of Heat and Mass Transfer, Vol. 14, No. 9, pp. 1377-1394.

Haverkamp, V., Hessel, V., Löwe, H., Menges, G., Warnier, M. J. F., Rebrov, E. V., Croon, M., Schouten, J. C., and Liauw, M. A., 2006, Hydrodynamics and Mixer-Induced Bubble Formation in Micro Bubble Columns with Single and Multiple Channels, Chemical Engineering \& Technology, Vol. 29, No. 9, pp. 1015-1026.

Huelle, Z. R., 1967, Heat Load Influences upon Evaporator Parameters, International Refrigeration and Air Conditioning Conference, Vol. 3, No. 32, pp. 985-999.

Huelle, Z. R., 1972, The MSS Line - a New Approach to the Hunting Problem, ASHRAE Journal, October, pp. 43-46.

Li, H., and Hrnjak, P., 2015, An Experimentally Validated Model for Microchannel Heat Exchanger Incorporating Lubricant Effect, International Journal of Refrigeration, Vol. 59, pp. 259-268.

Mader, G., Palm, B., and Elmegaard, B., 2015, Maldistribution in Airewater Heat Pump Evaporators. Part 1: Effects on Evaporator, Heat Pump and System Level, International Journal of Refrigeration, Vol. 50, pp. 207-216.

Mithraratne, P., and Wijeysundera, N. E., 2003, An Experimental and Numerical Study of Hunting in Thermostatic-Expansion-Valve Controlled Evaporator, International Journal of Refrigeration, Vol. 25, pp. 992-998.

Mueller, A. C., 1987, Effects of Some Types of Maldistribution on the Performance of Heat Exchanger, Heat Transfer Engineering, Vol. 8, No. 2, pp. 75-86.

Mueller, A. C., and Chiou, J. P., 1988, Review of Various Types of Flow Maldistribution in Heat Exchangers, Heat Transfer Engineering, Vol. 9, No. 2, pp. 36-50.

Rebrov, E. V., 2010, Two-phase Flow Regimes in Microchannels, Theoretical Foundations of Chemical Engineering, Vol. 44, No. 4, pp. 355-367.

Saisorn, S., and Wongwises, S., 2008, A Review of Two-Phase Gas-Liquid Adiabatic Flow Characteristics in Micro-Channels, Renewable and Sustainable Energy Reviews, Vol. 12, pp. 824-838.

Shang, Y., Wu, A., and Fang, X., 2015, A Study on the Modeling of the Minimal Stable Superheat for a Variable Speed Refrigeration System, International Journal of Refrigeration, Vol. 59, pp. 182-189.

Shannon, M. A., Leicht, T., M., Hrnjak, P. S., Miller, N. R., and Khan, F. A., 2001, Thin-film Resistance Sensor for Measuring Liquid Mass Fraction in Super-Heated Refrigerant, Sensors and Actuators A: Physical, Vol. 88, No. 2, pp. 164-177.

Shao, N., Gavriilidis, A., and Angeli, P., 2009, Flow Regimes for Adiabatic Gas-Liquid Flow in Microchannels, Chemical Engineering Science, Vol. 64, pp. 2749-2761.

Solberg, J., Miller, N., and Hrnjak, P., 2000, A Sensor for Estimating the Liquid Mass Fraction of the Refrigerant Exiting an Evaporator, SAE, Paper 200001-0976.

Sontag, R. E., Borgnakke, C., and Van Wylen, G. J., 2003, Fundamentals of Thermodynamics, 6th Edition, John Wiley \& Sons, Inc.

Thome, J. R., 1995, Comprehensive Thermodynamic Approach to Modeling RefrigerantLubricating Oil Mixtures, HVAC\&R Research, Vol. 1, No. 2, pp. 110-126.

Tuo, H., and Hrnjak, P., 2013, Effect of the Header Pressure Drop Induced Flow Maldistribution on the Microchannel Evaporator Performance, International Journal of Refrigeration, Vol. 36, No. 8, pp. 2176-2186.

Van der Meer, J. S., 1987, Simulation of a Refrigerant Evaporator, Doctoral Thesis, University of Technology, Delft, Netherlands.

Wallis, G. B., and Dobson, J. E., 1973, The Onset of Slugging in Horizontal Stratified Air-Water Flow, International Journal of Multiphase Flow, Vol. 1, No. 1, pp. 173-193.

Wedekind, G. L., and Stöecker, W. F., 1968, Theoretical Model for Predicting the Transient Response of the Mixture-Vapor Transition Point in Horizontal Evaporating Flow, Journal Heat Transfer, Vol. 90, No. 1, pp. 165-174.

Wedekind, G. L, 1971, An Experimental Investigation into the Oscillatory Motion of the Mixture-Vapor Transition Point in Horizontal Evaporating Flow, Journal Heat Transfer, Vol. 93, No. 1, pp.47-54.

Wedekind, G. L., Bhatt, B. L., and Beck, B. T., 1978, A System Mean Void Fraction Model for Predicting Various Transient Phenomena Associated with Two-Phase Evaporating and Condensing Flows, International Journal of Multiphase Flow, Vol. 4, No. 1, pp. 97-114.

Wei, W., Ding, G., Hu, H., and Wang, K., 2007, Influence of Lubricant Oil on Heat Transfer 
Performance of Refrigerant Flow Boiling Inside Small Diameter Tubes, Part 1: Experimental Study, Experimental Thermal and Fluid Science, Vol. 32, No. 1, pp. 67-76.

Worsøe-Schmidt, P., 1960, Some Characteristics of Flow Pattern and Heat Transfer of Freon-12 Evaporating in Horizontal Tubes, International Journal of Refrigeration, Vol. 40, pp. 40-44.

Wujek, S., 2011, Mist to Annular Flow Development Quantified by Novel Video Analysis Methods, Doctoral Thesis, University of Illinois at Urbana-Champaign, Urbana, USA.

Youbi-Idrissi, M., and Bonjour, J., 2008, The Effect of Oil in Refrigeration: Current Research Issues and Critical Review of Thermodynamic Aspects, International Journal of Refrigeration, Vol. 31, No. 2, pp. 165-179.

Zou, Y., and Hrnjak, P. S., 2014a, Effects of Fluid Properties on Two-Phase Flow and Refrigerant Distribution in the Vertical Header of a Reversible Microchannel Heat Exchanger-Comparing R245fa, R134a, R410A, and R32, Applied Thermal Engineering, Vol. 70, No. 1, pp. 966-976.

Zou, Y., and Hrnjak, P. S., 2014b, Effect of Oil on R134a Distribution in the Microchannel Heat Exchanger with Vertical Header, International Journal of Refrigeration, Vol. 40, pp. 201-210.

Zuber, N., and Staub, F. W., 1966, The Propagation and the Wave Form of the Vapour Volumetric Concentration in Boiling, Forced Convection System Under Oscillatory Conditions, International Journal of Heat and Mass Transfer, Vol. 9, No. 9, pp. 871-895 